\title{
Identification and Characterization of Novel Genetic Markers Associated with Biological Control Activities in Bacillus subtilis
}

\author{
Raghavendra Joshi and Brian B. McSpadden Gardener
}

Department of Plant Pathology, The Ohio State University, OARDC, 1680 Madison Ave., Wooster 44691. Accepted for publication 3 October 2005.

\begin{abstract}
Joshi, R., and McSpadden Gardener, B. B. 2006. Identification and characterization of novel genetic markers associated with biological control activities in Bacillus subtilis. Phytopathology 96:145-154.

Suppressive subtractive hybridization ( $\mathrm{SSH}$ ) was used to identify genetic markers associated with biological control of plant pathogens by Bacillus subtilis. The genomes of two commercialized strains, GB03 and QST713, were compared with that of strain 168 , which has no defined biocontrol capacities, to obtain a pool of DNA fragments unique to the two biocontrol strains. The sequences of 149 subtracted fragments were determined and compared with those present in GenBank, but only 80 were found to correspond to known Bacillus genes. Of these, 65 were similar to genes with a wide range of metabolic functions, including the biosynthesis of cell wall components, sporulation, and antibiotic biosynthesis. Sixteen subtracted fragments shared a high degree of similarity to sequences found in multiple $B$. subtilis strains with proven biocontrol capacities. Oligonucleotide primers specific to nine of these genes were developed. The targeted genes included five genes involved in antibiotic
\end{abstract}

ABSTRACT

Bacillus subtilis is omnipresent in agricultural soils, and some isolates have shown distinct capacities to suppress plant pathogens and otherwise improve plant health (27). For example, the strain BacB was found to decrease disease severity of Cercospora leaf spot on sugar beet (6), strain CL27 can inhibit Botrytis cinerea in seedlings (19), and strain GA1 can colonize apple pulp and reduce gray mold infections (52). Some strains secrete antibiotics that can directly inhibit the growth of fungal, oomycete, and bacterial plant pathogens $(4,9,26,52)$. The types and amounts of antibiotics produced are known to vary by strain and cultivation medium (2). Some other strains of Bacillus subtilis suppress diseases by inducing host defenses (14). For example, B. subtilis IN937b was able to reduce the incidence and severity of disease caused by Tomato mottle virus (35). However, it is likely that the most effective biological control strains will act via multiple mechanisms. For example, strain M4 can inhibit fungal pathogens directly through antibiosis, but it also was found to induce resistance to foliar pathogens when it was applied to the plant root $(37,38)$.

Intensive screening and field testing has led to the commercial development of diverse Bacillus strains as biological control agents (29). The U.S. Environmental Protection Agency currently maintains a listing of biopesticides registered for pest and disease

Corresponding author: B. B. McSpadden Gardener; E-mail address: bbmg+@osu.edu

* The $\boldsymbol{e}$-Xtra logo stands for "electronic extra" and indicates that the online version contains supplemental material not included in the print edition. Sequence alignments of individual gene fragments and $\mathrm{NJ}$ trees of aligned sequences are provided.

DOI: 10.1094/PHYTO-96-0145

(C) 2006 The American Phytopathological Society synthesis $(b m y B, f e n D$, ituC, srfAA, and $\operatorname{srf} A B)$ and four additional genes (yndJ, yngG, bioA, and a hypothetical open reading frame) not previously associated with biological control. All nine markers were amplified from the commercialized B. subtilis strains GB03, QST713, and MBI600, with the exception of $i t u C$, which was not detected in GB03. The markers also were amplified from four other $B$. subtilis isolates, but they were not amplified from other related Bacillus strains, including the plant growthpromoting rhizobacteria IN937a and IN937b. Sequencing of the amplified markers revealed that all seven of the isolates that scored positive for multiple markers were genotypically distinct strains. Interestingly, strains scored positive for the amplifiable markers generally were more effective at inhibiting the growth of Rhizoctonia solani and Pythium ultimum than other Bacillus isolates that lacked the markers. The potential utility of the defined genetic markers to further define the diversity, ecology, and biocontrol activities of B. subtilis are discussed.

Additional keywords: cyclic lipopeptides, genetic diversity, plant growth promotion. control in the United States (provided online by the Environmental Protection Agency). The product Kodiak (Gufstafson Biologicals, Plano, TX) contains B. subtilis strain GB03 and is labeled for control of root pathogens such as Fusarium spp., Aspergillus spp., Rhizoctonia solani, and Alternaria spp. in cotton, peanut, soybean, and vegetables. The principal component of Serenade (Agraquest Inc., Davis, CA) is B. subtilis strain QST713; this product is labeled for the management a variety of plant diseases, including early blight, fire blight, downy mildew, and tomato leaf spots. Subtilex (Becker Underwood, Ames, IA) contains $B$. subtilis strain MBI600, which has been indicated for use against Fusarium, Aspergillus, and Rhizoctonia spp. on roots of soybean and peanut and against Botrytis spp. infection of vines, strawberry, and cucumber, powdery mildew of tomato, and brown rust of cereals. A number of $B$. subtilis strains have been integrated successfully into several pest management programs (13). For example, Fusarium wilt of chickpea was suppressed more effectively by $B$. subtilis GB03 on the partially resistant cultivar than on a susceptible cultivar (11).

Still, the genetic basis for biological control of plant pathogens by $B$. subtilis strains is not fully understood. To date, most work has focused on antibiotic production. Many strains of B. subtilis produces cyclic lipopeptides (CLPs), antibiotic compounds synthesized nonribosomally by large peptide synthetases (23). Several CLPs have been associated with plant pathogen suppression. For example, iturins and surfactin have been shown to be active against $R$. solani (4), and pure fengycin has been found to inhibit Pyricularia oryzae (21). Genetic disruption of iturin biosynthesis has been shown to decrease the capacity of strain RB14 to suppress $R$. solani (53). More recently, mutant analyses in $B$. subtilis subsp. amyloliquefaciens strain FZB42 have indicated that fengycin and bacillomycin D act synergistically to inhibit the growth of 
Fusarium oxysporum in vitro (15). The occurrence of CLPmediated antibiosis has led to the suggestion that non-ribosomal peptide synthetases may be used as markers for identifying and selecting novel biocontrol agents from environmental samples (10). However, the recent discovery that multiple mechanisms for biological control and plant growth promotion can occur in some strains of B. subtilis $(44,45)$ indicates that such an approach would be far from comprehensive.

The complete genome sequence of B. subtilis strain 168 has been used successfully to advance our understanding of microbial physiology of B. subtilis (48). However, strain 168 has no known activities related to the biological control of plant pathogens. Because of this, genomic comparisons with proven biocontrol strains should provide insights into the genetic basis for biological control in this species. In this study, suppressive subtractive hybridization (SSH) (1) was used to screen the genomes of GB03 and QST713 for strain-specific genetic elements that could be related to biological control. This approach was used recently to identify gene fragments associated with rhizosphere competence in different biocontrol strains of Pseudomonas fluorescens (25). Furthermore, a sequence homologous to a bacteriocin obtained in that study led to the discovery of a population of biocontrol P. fluorescens that produced bacteriocins and had antagonistic activity against other isolates. These strains competed in wheat rhizosphere for establishment of effective population size (54). Here, we report on the identification, characterization, and association of several genetic markers with biological control of plant pathogens by B. subtilis.

\section{MATERIALS AND METHODS}

Strain isolation and maintenance. B. subtilis subsp. subtilis 168 was obtained from the Bacillus Genetic Stock Center at The Ohio State University, Columbus. B. subtilis strains GB03, QST 713 , and MBI600 were isolated from the commercialized biological control products Kodiak (Gufstafson Biologicals LLC), Serenade (Agraquest Inc.), and Subtilex (Becker Underwood), respectively. A collection of 66 additional Bacillus isolates was assembled for genetic and phenotypic comparisons. Most were recovered from the soils of Ohio soybean fields located in Delaware, Henry, Huron, Mercer, or Wayne Counties. To recover these isolates, $1 \mathrm{~g}$ of soil was placed in $5 \mathrm{ml}$ of sterile distilled water, vortexed, heated to $65^{\circ} \mathrm{C}$ for $20 \mathrm{~min}$, and plated on $1 / 10 \times$ tryptic soy agar (TSA) (3 g of tryptic soy extract and $15 \mathrm{~g}$ of agar per liter) containing cycloheximide at $100 \mu \mathrm{g} / \mathrm{ml}$. The cultures were incubated at room temperature or at $45^{\circ} \mathrm{C}$ to select for members of the B. subtilis group for up to 2 days prior to selection of individual isolates. Ten additional strains were used to determine the specificity of the genetic markers obtained in this study. Eight strains, B. cereus $6 \mathrm{~A} 15, B$. licheniformis 5A1, B. megaterium 7A2, B. mycoides 6A20, B. pumilus 8A3, B. sphaericus 13A5, $B$. subtilis 1A748, and B. thuringiensis 4A1, were obtained from the Bacillus Genetic Stock Center. The plant growth-promoting B. subtilis strains IN937a and IN937b were kindly provided by J. Kloepper (Auburn, AL), B. pumilus GB34 was isolated from Yield Shield (Gufstafson Biologicals) and a second isolate of strain GB03 was obtained from Companion (Growth Products Ltd., White Plains, NY). All of the isolates were identified to species based on restriction analyses or partial sequencing of amplified 16S rRNA gene sequences using the genus-specific primers Ba1F (5'-ACG GGT GAG TAA CAC GTR GGY AAC) and Ba2R (5'-ACC TTC CTC CGG TTT GTA ACC GGC) (27). Additionally, four pathogens isolated from soybean, Pythium irregulare strain W18, P. ultimum strain 19, Phytophthora sojae strain $\mathrm{R}-25$, and $R$. solani strain NT15, were provided to us by A. Dorrance, Department of Plant Pathology, The Ohio State University. All of these cultures were maintained on $1 / 10 \times$ TSA at room temperature up to 1 week prior to use in various assays. For long- term storage, the same media amended with $17 \%$ glycerol was used and isolates were stored at $-80^{\circ} \mathrm{C}$.

Genomic subtraction. Template DNA was isolated and purified by using the Wizard Genomic DNA purification kit and protocol (Promega Corp., Madison, WI). SSH was performed using the polymerase chain reaction (PCR) Select Bacterial Genome Subtraction Kit (Clontech Laboratories, Palo Alto, CA) according to the manufacturer's instructions. Genome subtraction was performed for two tester strains, QST713 and GB03, and a single driver, strain 168. The genomic DNA of each strain was digested with $R s a \mathrm{I}$. The tester DNA was divided into two pools, and each pool was ligated with a different adapter at the $5^{\prime}$ end. Excess driver DNA then was hybridized to both pools. Both pools then were mixed together and excess of the denatured driver was added again in a thermal cycler (MJ Research Corp.). A PCR with adapter-specific sequences was performed to amplify tester-specific sequences. Another amplification was performed with nested primers for the adapters to obtain a highly enriched pool of testerspecific sequences. The following primers were used for amplification: primer 1 (5'-CTAATACGACTCACTATAGGGC), nested primer 1 (5'-TCGAGCGGCCGCCCGGGCAGGT), and nested primer 2R (5'-AGCGTGGTCGCGGCCGAGGT). The adapters were adapter 1 (5'-CTAATACGACTCACTATAGGGCTCGAGCGGCCGCCCGGGCAGGT) and adapter 2R (5'-CTAATACGACTCACTATAGGGCAGCGTGGTCGCGGCCGAGGT). Amplifications were performed according to the manufacturer's instructions. The tester-enriched mix obtained from the genome subtraction was cloned into pGEM-T vector (Promega Corp.) and the plasmids were introduced into Escherichia coli JM109 cells by heat shock following the manufacturer's protocol. Transformants were selected on Luria Bertani (LB) agar amended with ampicillin $(120 \mu \mathrm{g} / \mathrm{ml})$, IPTG, and X-gal. From the subtraction of each strain, 192 white colonies were picked up and a subtracted clone library for each strain was generated. These libraries are stored at $-80^{\circ} \mathrm{C}$ in liquid LB with $17.5 \%$ glycerol.

Characterization of cloned sequences. Plasmids were isolated from the transformed cells using the QiaPrep Spin Miniprep kit (Qiagen Inc., Valencia, CA). Nested primer 1 and nested primer $2 \mathrm{R}$, which were designed to anneal to the adapters on both $5^{\prime}$ and $3^{\prime}$ ends of every insert, were used to amplify the subtracted DNA according to the manufacturer's instructions. The amplified fragments were purified by the Wizard SV gel and PCR clean-up kit (Promega Corp.). The inserts then were submitted to the OARDC's Molecular and Cellular Imaging Center (Wooster, $\mathrm{OH}$ ) for single-pass sequencing using nested primer 1 . The determined sequences were compared with GenBank using the BLAST N and BLAST X software provided online by the National Center for Biotechnology Information. (3).

Development of PCR assays. The selected DNA sequences were aligned with their corresponding homologs in two or more biocontrol Bacillus strains. Sites that showed $>80 \%$ identity to the cloned sequences were selected as potential priming sites. The primers designed had a $\mathrm{C}$ or $\mathrm{G}$ at the $3^{\prime}$ end. Primers were analyzed for hairpins and dimers by the web-based program, NetPrimer (Premier BioSoft International, Palo Alto, CA). The reaction volume was $25 \mu \mathrm{l}$ and included $2 \mu \mathrm{l}$ of the genomic DNA, $1 \times$ Taq DNA polymerase buffer (Promega Corp.), $1.5 \mathrm{mM} \mathrm{MgCl}_{2}$, and $200 \mu \mathrm{M}$ each dATP, dTTP, dGTP, and dCTP (Invitrogen Technologies). The following cycling conditions were used to amplify all the targets: $95^{\circ} \mathrm{C}$ for $4 \mathrm{~min}, 30$ cycles of $94^{\circ} \mathrm{C}$ for $1 \mathrm{~min}$, annealing temperature for $1 \mathrm{~min}$, and $70^{\circ} \mathrm{C}$ for $1 \mathrm{~min}$. A final extension step of $70^{\circ} \mathrm{C}$ for $5 \mathrm{~min}$ was followed by a $4^{\circ} \mathrm{C}$ soak. An annealing temperature of $62^{\circ} \mathrm{C}$ allowed for amplification of the intended targets from strains GB03, QST713, and MBI600. However, for screening the Bacillus collection for the presence of the markers, the lower annealing temperatures generally were used. Specifically, the annealing temperature for $f e n D, b m y B$, ituC, $y n d J$, and bioA specific primer sets was set to $52^{\circ} \mathrm{C}$, whereas 
those for $\operatorname{srfAA}$, srfAB, yngG, and clone Q044 were set to 62, 58, 54 , and $50^{\circ} \mathrm{C}$, respectively. Amplifications were carried out in a PTC200 thermocycler (MJ Research). The amplified products were resolved on a $1.8 \%$ agarose gel in $0.5 \times$ Tris-borate EDTA (TBE) for $2.5 \mathrm{~h}$ at $140 \mathrm{~V}$ and visualized after staining with ethidium bromide. Size comparisons were made with a 100-bp DNA ladder (New England Biolabs, Boston). Gel images were captured with the imaging system (Kodak DC120; Kodak, Rochester, NY).

Phylogenetic analysis of genes correlated with biocontrol activities. DNA fragments from three CLP synthetases (fenD, bmy $B$, and $\operatorname{srfAA}$ ) and three other genes (yndJ, yngG, and bioA) were amplified and sequenced from seven isolates (GB03, MBI600, QST713, 2.2a, 2,4a, 2,4d, and 2.6a) using the genespecific PCR primers developed for each. The GenBank accession numbers for these sequences are DQ011324-30 (bmyB), DQ011331-37 (fenD), DQ011338-44 (bioA), DQ011345-51 (yngG), DQ011352-58 (srfAA), and DQ011359-65 (yndJ). Forward and reverse sequence data were compiled using Sequencher (Gene Codes Corporation, Ann Arbor, MI) and subsequently aligned and analyzed using Clustal X 1.8.1 (51) Additional phylogenetic analyses were performed using concatenated sequences assembled prior to analysis. Dendrograms were visualized using NJ Plot (39).

Inhibition assays. The ability of the different Bacillus isolates to inhibit four different plant pathogens (i.e., Pythium irregulare W18, P. ultimum 19, Phytophthora sojae R-25, and $R$. solani NT15) was determined using in vitro plate assays as described previously (44). Briefly, bacteria were cultured in $1 / 10 \times$ tryptic soy broth $(3 \mathrm{~g} /$ liter $)$ for 24 to $48 \mathrm{~h}$. Each culture $(5 \mu \mathrm{l})$ was placed at four edges of a 1/10× TSA plate, and an agar plug containing the pathogen was placed at the center. For P. sojae, four agar plugs of the pathogen were placed at four corners of the plate and bacterial cultures were placed between the plugs. Four independent replicates of each bacterial isolate were used to assess the growth inhibition of each pathogen. The plates were incubated at room temperature for up to 15 days, depending on the radial growth rate of each pathogen. Pythium ultimum plates were scored after 2 days, $P$. irregulare after 5 days, Phytophthora sojae after 15 days, and $R$. solani after 6 days. An ordinal scale was used to rate the inhibition, with 0 representing no inhibition, 1 representing intermediate, and 2 representing maximum inhibition observed for each pathogen. Under the assay conditions used, the size of the inhibition zones of the $R$. solani and $P$. sojae cultures ranged up to $10 \mathrm{~mm}$, with zones of $<2 \mathrm{~mm}$ scored 1 and zones $\geq 2 \mathrm{~mm}$ scored 2. In contrast, inhibition of the Pythium strains was generally minimal (i.e., $<2-\mathrm{mm}$ inhibition zones) and distinctions were made by visually scoring the relative density of hyphae approaching the edge of the spotted bacteria (i.e., with some and no hyphae present within $2 \mathrm{~mm}$ of the bacterial spot being scored as 1 and 2, respectively). The mean score of four independent replicates of each isolate were used for statistical comparisons. Nonparametric comparisons of inhibition scores were made using the Kruskal-Wallis test available in Minitab (version 14.0).

\section{RESULTS}

Characterization of strain-specific DNA fragments. In order to identify DNA markers for biological control in B. subtilis, SSH was conducted to identify sequences present in the genomes of strains GB03 and QST713 but absent in the genome of strain 168 . In all, 149 subtracted fragments (74 from GB03 and 75 from QST713) were cloned and analyzed. Fragment lengths varied from 180 to $1,520 \mathrm{bp}$, with a median fragment size of $560 \mathrm{bp}$. Sequence analyses revealed that 80 of the subtracted fragments (36 from GB03 and 44 from QST713) had significant nucleotide homology ( $E$ value $<1 \mathrm{E}-4)$ to previously identified Bacillus sequences. The sequences of these fragments can be found in
GenBank under accession numbers DQ011366-401 (GB03) and DQ0113402-446 (QST713) in the same order as presented in Tables 1 and 2, respectively. In several instances, clones from both strains GB03 and QST713 were identified that had similarity to gene fragments from homologous operons. These included genes for the biosynthesis of cyclic lipopeptides (bam/bmy, fen, and $s r f$ ) and the cell wall component teichuronic acid (tua). Subtracted fragments matching the $y$ ndJ gene from B. subtilis subsp. amyloliquefaciens strain FZB42 also were recovered from both strains GB03 and QST713. Additionally, multiple sporulation gene fragments (spo) were found in both subtracted libraries.

Thirteen cloned fragments shared an average of $94 \%$ nucleotide identity with DNA from the biocontrol strain FZB42 (15). Additionally, three other fragments were 88,90 , and $94 \%$ identical to sequences known to be present in other biocontrol strains of B. subtilis (i.e., AU195 [34], RB14 [4], and A1/3 [12], respectively). This level of sequence identity was significantly higher than the $84 \%$ identity shared by 40 fragments which were more similar to those found in strain 168 than any other sequences currently present in GenBank $(P<0.001)$. The genes found to be common among multiple biocontrol strains were predominantly those encoding for the biosynthesis of cyclic lipopeptide antibiotics (i.e., bam/bmy, fen, itu, and srf genes). However, others were similar to genes of unknown function ( $y n d J, y n g G$, and yoxA) or matched unannotated regions of the FZB42 genome. Interestingly, two pairs of genes with unknown functions are closely linked to one another on the genome of FZB42. For example, clone Q044 maps to a hypothetical open reading frame (ORF) just $2.5 \mathrm{~kb}$ from $y n d J$, and bioA is proximal to the $y n g G$ locus. Additionally, the yoxA gene is just $2 \mathrm{~kb}$ downstream of the $f e n A$ gene. These data indicated that multiple gene sequences are shared by different strains with proven biocontrol potential.

Selection of putative targets and development of PCR-based assays. From the 80 clones, 15 sequences were chosen for development as putative markers for biocontrol in B. subtilis. Specifically, sequences from the coding regions of $\operatorname{srfAA}$, srfAB (coding for surfactin synthetases), fen $C$, fenD (coding for fengycin synthetase), bamA, bmyB (coding for bacillomycin synthetase), ituC (coding for iturin synthetase), tuaB, tuaE (coding for teichuronic acid biosynthesis), bioA (involved in biotin biosynthesis), yndJ, $y n g G$, yoxA, and the predicted ORF from FZB42 aligning to clone Q044 were chosen as targets for PCR-based assays. The sequences cloned from GB03 and QST713 were aligned with homologous ORFs present in other known biocontrol strains and strain 168. From those alignments, potentially useful priming sites were identified and the corresponding primer sets were analyzed using the NetPrimer software. In all, 22 primer sets were designed for evaluation.

Initial testing involved the use of strain 168 and three commercialized biocontrol strains of B. subtilis: GB03, QST713, and MBI600. Preliminary attempts to optimize the PCR-based amplification of the intended targets were successful for only 9 of the 15 targets. The primer sets for which useful assays were subsequently developed are described in Table 3. Prior to the start of these experiments, fewer than five of the targeted genes were known to occur in any single biocontrol strain of $B$. subtilis. Remarkably, all nine targets were amplified successfully from strains QST713 and MBI600, and all except for ituC were amplified from strain GB03 (Fig. 1). None of the targeted DNA fragments were amplified from the genome of strain 168, which has no known biocontrol activities.

To further assess the utility of the PCR primers, we tested a collection of 66 Bacillus strains for the presence of all nine gene fragments. DNA products of the expected size were efficiently amplified solely from a subset of the B. subtilis present in our collection. All nine fragments were efficiently amplified from four B. subtilis isolates (i.e., 2.2a, 2.4a, 2.4d, and 2.6a) obtained from Ohio soybean fields, and all but $i t u C$ were amplified from 
the GB03 strain isolated from Companion. However, only the $b m y B$ gene was detected in strains IN937a and IN937b. In contrast, relatively weak amplifications of products of the expected size were obtained using six other isolates obtained from Ohio soils. B. pumilus isolate $1.1 \mathrm{a} 2$ and $B$. licheniformis isolate $1.4 \mathrm{c} 2$ from Ohio were scored positive for five (yndJ, $\operatorname{srf} A B$, bymB, bioA, and $i t u C)$ and two $(\mathrm{Q} 044$ and $y n g G)$ of the nine gene fragments, respectively. In addition, $B$. pumilus isolates $2.5 \mathrm{a}, 5 \mathrm{~A} 1 \mathrm{a} 1$, and $6.4 \mathrm{c} 1$ each were scored positive for only one fragment (i.e., $b m y B$, yng $G$, and $\operatorname{srfAA}$, respectively). Otherwise, DNA products of the expected sizes were not amplified from the $B$. licheniformis, B. pumilus, and B. subtilis strains in our collection, including the commercialized biocontrol strain GB34. B. cereus, $B$. mycoides, and $B$. thuringiensis strains all were scored negative for the putative markers, with the exception that one of two faint bands amplified from most $B$. cereus strains comigrated with the $i t u C$ product amplified from the positive control strain, QST713.

Sequence analyses of six amplified gene fragments. We further characterized the genetic diversity of B. subtilis strains from which all nine of the targeted gene fragments could be amplified. Specifically, we performed sequence analyses for the portions of bmyB, fenD, srfAA, bioA, $y n g G$, and $y n d J$ that were amplified from strains GB03, QST713, MBI600, 2.2a, 2.4a, 2.4d, and 2.6a. Pairwise sequence comparisons revealed a very high degree of nucleotide conservation across the six concatenated gene sequences, ranging from 97 to $99 \%$ sequence identity. Additionally, consensus sequences from alignments of all seven isolates examined were 93 to $98 \%$ identical, depending on which sequence was analyzed. Notably, all of the sequences were unique except for the portions of $y n d J$ and srfAA amplified from 2.4a, 2.4d, and 2.6a, which all were identical. When compared with GenBank, the 42 cloned sequences had the highest degree of similarity (i.e., $>93 \%$ nucleotide identity and $>91 \%$ amino acid identity) to homologous sequences previously identified in other biocontrol strains (i.e., FZB42, RB14, and AU195). In contrast, the sequences amplified from the seven isolates were much less similar to those found in strain 168 and other Bacillus strains with no proven biocontrol activity. With regards to strain 168 , blastn searches could identify significant matches only to bioA and $y n d J$ gene sequences (83 and $86 \%$ identity), and blastx searches revealed $<77 \%$ amino acid identity to five of the six genes. The exception was the $b m y B$ fragment that shared $95 \%$ amino acid identity with the nonfunctional bamA sequence previously characterized in strain 168 . These data indicated that the gene fragments targeted by our primer sets (Table 3) can be found in different B. subtilis isolates that have been marketed successfully as biological control agents.

Because of the limited amount of nucleotide sequence available for each of the six gene fragments evaluated, phylogenetic analyses of concatenated sequences (Fig. 2) were used to evaluate the evolutionary relatedness of the isolates from which eight or nine of the elements could be amplified. These analyses indicated that three of the Ohio isolates $(2.4 \mathrm{a}, 2.4 \mathrm{~d}$, and 2.6a) were closely

TABLE 1. Identification of subtracted genome fragments obtained from Bacillus subtilis GB03

\begin{tabular}{|c|c|c|c|c|c|c|}
\hline Clone number & Fragment length $^{\mathrm{a}}$ & Sequenced length ${ }^{b}$ & E value blastn & $\mathrm{E}$ value blastx ${ }^{\mathrm{c}}$ & Organism $^{\mathrm{d}}$ & $\mathrm{Gene}^{\mathrm{e}}$ \\
\hline G002 & 1,200 & 503 & 0 & $3 \mathrm{E}-38$ & Ba FZB42 & bioA \\
\hline G114 & 800 & 621 & $1 E-166$ & $1 \mathrm{E}-34$ & Ba FZB42 & yoxA \\
\hline G011 & 580 & 315 & $1 \mathrm{E}-158$ & $3 E-41$ & Ba FZB42 & srfAA \\
\hline G080 & 450 & 369 & $1 \mathrm{E}-131$ & $3 E-46$ & Ba FZB42 & fenD \\
\hline G006 & 1,150 & 607 & $1 \mathrm{E}-127$ & $2 \mathrm{E}-37$ & Ba FZB42 & yndJ \\
\hline G110 & 517 & 325 & $1 \mathrm{E}-122$ & $7 E-40$ & Ba FZB42 & $\operatorname{srf} A B$ \\
\hline G108 & 500 & 348 & $1 E-117$ & $3 E-44$ & $B a$ & $s a c B$ \\
\hline G003 & 700 & 361 & $1 \mathrm{E}-111$ & $3 \mathrm{E}-28$ & Bs AU195 & bamA \\
\hline G119 & 380 & 309 & $3 E-83$ & $6 \mathrm{E}-48$ & Bs 168 & rров \\
\hline G007 & 500 & 375 & $4 \mathrm{E}-52$ & $2 \mathrm{E}-47$ & Bs 168 & menB \\
\hline G050 & 485 & 415 & $1 E-43$ & $1 \mathrm{E}-55$ & Bs 168 & spoVJ \\
\hline G057 & 600 & 421 & $2 \mathrm{E}-39$ & $1 \mathrm{E}-63$ & Bs & NA \\
\hline G081 & 520 & 448 & $2 \mathrm{E}-39$ & $1 \mathrm{E}-54$ & Bs 168 & $\operatorname{aspS}$ \\
\hline G028 & 700 & 392 & $3 E-34$ & $7 \mathrm{E}-60$ & Bs 168 & $g \ln M$ \\
\hline G094 & 460 & 327 & $1 \mathrm{E}-33$ & $3 \mathrm{E}-34$ & Bs 168 & kinE \\
\hline G083 & 700 & 505 & $2 \mathrm{E}-33$ & $8 \mathrm{E}-38$ & Bs 168 & spoIIIAE \\
\hline G113 & 320 & 253 & $1 E-29$ & $2 \mathrm{E}-17$ & Bs 168 & $l p d V$ \\
\hline G111 & 500 & 384 & $5 E-24$ & $4 \mathrm{E}-44$ & Bs 168 & moaE \\
\hline G104 & 460 & 381 & $7 E-20$ & $7 \mathrm{E}-37$ & Bs 168 & pyrAA \\
\hline G035 & 1,050 & 602 & $2 E-18$ & $3 \mathrm{E}-79$ & Bs & dnaE \\
\hline G102 & 750 & 427 & $5 E-18$ & $1 \mathrm{E}-29$ & $B s$ & $x t m B$ \\
\hline G101 & 900 & 468 & $2 \mathrm{E}-17$ & $1 \mathrm{E}-12$ & Bs 168 & bsn \\
\hline G079 & 480 & 376 & $3 E-16$ & $3 E-34$ & Bs 168 & $d a p B$ \\
\hline G078 & 400 & 346 & $1 \mathrm{E}-15$ & $5 \mathrm{E}-32$ & Bs & pyrC \\
\hline G112 & 550 & 394 & $1 \mathrm{E}-15$ & $8 \mathrm{E}-58$ & $B l$ & murE \\
\hline G073 & 900 & 445 & $2 \mathrm{E}-11$ & $6 \mathrm{E}-37$ & $B l$ & $y v c H$ \\
\hline G086 & 380 & 280 & $7 \mathrm{E}-10$ & $4 \mathrm{E}-25$ & Bs & $t u a B$ \\
\hline G109 & 1,000 & 639 & 7E-09 & $2 \mathrm{E}-43$ & Bs 168 & $y b f G$ \\
\hline G089 & 250 & 181 & $3 \mathrm{E}-08$ & $5 \mathrm{E}-11$ & Bs 168 & $y w b D$ \\
\hline G032 & 410 & 237 & $1 \mathrm{E}-07$ & $9 E-39$ & Bs 168 & $y j c G$ \\
\hline G085 & 650 & 503 & $5 E-06$ & NA & Bs 168 & $y d a B$ \\
\hline G012 & 510 & 238 & 9E-06 & $3 \mathrm{E}-10$ & Bs & $y s x E$ \\
\hline G096 & 1,200 & 428 & $2 \mathrm{E}-05$ & $2 \mathrm{E}-27$ & $B l$ & $y j i B$ \\
\hline G116 & 250 & 179 & $3 \mathrm{E}-05$ & $3 \mathrm{E}-14$ & $B s$ & cheV \\
\hline G087 & 450 & 325 & $5 \mathrm{E}-05$ & $4 \mathrm{E}-34$ & $B l$ & yveS \\
\hline G092 & 700 & 445 & $7 \mathrm{E}-05$ & $3 E-39$ & $B s$ & $y v k C$ \\
\hline
\end{tabular}

${ }^{\text {a }}$ Length of sequence obtained after suppressive subtractive hybridization.

${ }^{b}$ Length of sequence used for BLAST-based comparisons to GenBank.

c NA indicates not applicable because no blastx matches were found in GenBank for this clone.

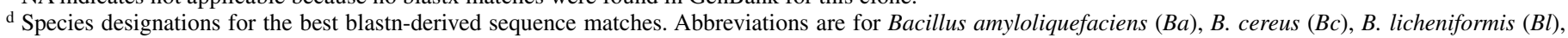
or B. subtilis $(B s)$. Strain names are listed only for previously identified biocontrol strains and the reference strain 168.

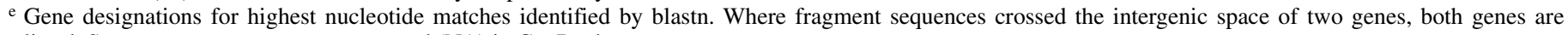
listed. Some sequences were not annotated (NA) in GenBank. 
related to but evolutionarily distinct from all other isolates. The strong bootstrap support (i.e., $>850$ of 1,000 iterations) for branching events highlights the degree to which the strains differed across the six loci being examined (Fig. 2A). Similar evolutionary relationships were apparent when only the genes for antibiotic biosynthesis were considered (Fig. 2B). Analyses using the other three gene fragments (bioA, $y n d J$, and $y n g G$ ) resulted in branching patterns with much less bootstrap support, indicating more ambiguous evolutionary relationships among all of the strains (data not shown). Additional analyses also were performed using the DNApars and DNAml programs of the phylogeny inference package (PHYLIP) software, but these applications generated results that were essentially identical to those generated by the neighbor-joining algorithm of CLUSTAL X (data not shown).

Inhibition of plant pathogens associated with the presence of targeted sequences. We tested 66 different Bacillus isolates, most isolated from Ohio soybean fields, for their ability to inhibit the growth of four different soilborne plant pathogens of soybean in vitro. B. subtilis isolates that harbored at least eight of the nine gene fragments defined above generally were more effective at inhibiting the growth of $R$. solani and Pythium ultimum in vitro than the other isolates tested ( $P=0.001$ and 0.003 , respectively). This association is indicated in Figure 3, where the average $(n=$ 4) in vitro inhibition scores of B. subtilis strains harboring the amplifiable markers were ranked, on average, in the $91 \mathrm{st}$ and 72nd percentiles of all Bacillus isolates tested in vitro against $R$. solani and P. ultimum, respectively.

The association of the assayed markers and in vitro inhibition capacities of individual isolates varied depending on the pathogen being challenged. In the case of $R$. solani, all of the isolates harboring at least eight of the targeted markers had average $(n=4)$ inhibition scores of 1.75 to 2.0, whereas all those lacking the markers averaged $<1.0$, except GB34, which had a score of 2.0. In most pairwise comparisons, these differences in in vitro inhibition scores between the two types of isolates were statistically significant $(P<0.05)$. In the case of $P$. ultimum, all of the isolates harboring all nine genes were maximally inhibitory (i.e., had a score of 2.0), but so were a nearly equal number of other Bacillus iso-

TABLE 2. Identification of subtracted genome fragments obtained from Bacillus subtilis QST713

\begin{tabular}{|c|c|c|c|c|c|c|}
\hline Clone number & Fragment length $^{\mathrm{a}}$ & Sequenced length $^{b}$ & E value blastn & E value blastx & Organism $^{\mathrm{c}}$ & Gene $^{\mathrm{d}}$ \\
\hline Q147 & 520 & 491 & 0 & $4 \mathrm{E}-85$ & Ba FZB42 & yndJ \\
\hline Q135 & 600 & 485 & 0 & $1 \mathrm{E}-65$ & $\mathrm{Ba}$ FZB42 & $y n g G$ \\
\hline Q137 & 720 & 615 & 0 & $9 \mathrm{E}-62$ & Bs RB14 & $i t u C$ \\
\hline Q042 & 560 & 461 & $1 \mathrm{E}-140$ & $3 E-62$ & $B a$ & NA \\
\hline Q014 & 500 & 273 & $1 \mathrm{E}-139$ & $1 \mathrm{E}-17$ & $\mathrm{Ba}$ FZB42 & $\mathrm{fenC}$ \\
\hline Q162 & 517 & 450 & $1 \mathrm{E}-125$ & $3 E-41$ & $\mathrm{Ba}$ FZB42 & $b m y B$ \\
\hline Q037 & 900 & 691 & $1 \mathrm{E}-108$ & $3 E-52$ & Bs 168 & $\operatorname{atpF}$ \\
\hline Q136 & 517 & 444 & $3 E-87$ & $2 \mathrm{E}-67$ & Bs 168 & iolG \\
\hline Q044 & 280 & 218 & $2 \mathrm{E}-86$ & $6 \mathrm{E}-21$ & Ba FZB42 & NA \\
\hline Q166 & 300 & 261 & $4 \mathrm{E}-85$ & $3 E-22$ & Bs 168 & yaaT \\
\hline Q154 & 320 & 208 & $3 E-82$ & $3 E-25$ & Bs 168 & yaaT/yabA \\
\hline Q161 & 600 & 510 & $3 E-75$ & $1 \mathrm{E}-50$ & Bs 168 & purK/purB \\
\hline Q023 & 1,100 & 191 & $2 \mathrm{E}-74$ & $1 \mathrm{E}-01$ & Bs A1/3 & eriG \\
\hline Q157 & 490 & 408 & $6 \mathrm{E}-67$ & $3 E-65$ & Bs 168 & $y f k B$ \\
\hline Q041 & 1,075 & 518 & $3 \mathrm{E}-60$ & $6 \mathrm{E}-87$ & Bs 168 & glpK \\
\hline Q024 & 1,130 & 572 & $1 E-59$ & $3 E-18$ & Ba FZB42 & $\operatorname{srfAA}$ \\
\hline Q128 & 320 & 275 & $1 \mathrm{E}-57$ & $2 \mathrm{E}-42$ & Bs 168 & gutP \\
\hline Q158 & 320 & 235 & $6 \mathrm{E}-47$ & $4 \mathrm{E}-17$ & Bs 168 & yazC/yacO \\
\hline Q144 & 600 & 510 & $7 E-36$ & $5 E-63$ & Bs 168 & $d p p C$ \\
\hline Q163 & 1000 & 827 & $3 E-33$ & $5 E-16$ & Bs 168 & $y c d H / y c d L$ \\
\hline Q167 & 480 & 310 & $1 \mathrm{E}-30$ & $3 E-35$ & Bs 168 & terC \\
\hline Q039 & 1400 & 637 & $9 \mathrm{E}-30$ & 0.26 & $B a$ & NA \\
\hline Q155 & 480 & 351 & $2 \mathrm{E}-29$ & $2 \mathrm{E}-29$ & Bs 168 & terC \\
\hline Q134 & 900 & 608 & $1 \mathrm{E}-25$ & $2 \mathrm{E}-65$ & Bs 168 & ориBC \\
\hline Q018 & 1,220 & 371 & $3 \mathrm{E}-25$ & $2 \mathrm{E}-48$ & Bs 168 & spoIIIC \\
\hline Q019 & 1,000 & 423 & $2 \mathrm{E}-23$ & $5 \mathrm{E}-01$ & Bs 168 & srfAA \\
\hline Q146 & 210 & 202 & $2 \mathrm{E}-21$ & $1 \mathrm{E}+00$ & $B s$ & NA \\
\hline Q066 & 350 & 285 & $2 \mathrm{E}-19$ & $7 \mathrm{E}-25$ & Bs 168 & $\operatorname{tag} O$ \\
\hline Q067 & 517 & 511 & $4 \mathrm{E}-19$ & $3 E-67$ & Bs 168 & thiF \\
\hline Q061 & 550 & 332 & $4 \mathrm{E}-15$ & $2 \mathrm{E}-34$ & Bs 168 & $y v g P$ \\
\hline Q017 & 870 & 479 & $5 \mathrm{E}-15$ & $1 \mathrm{E}-70$ & Bs 168 & yojI \\
\hline Q130 & 580 & 525 & $1 \mathrm{E}-12$ & $3 E-48$ & Bs & $r i b C$ \\
\hline Q069 & 1,000 & 588 & $2 \mathrm{E}-12$ & $8 \mathrm{E}-15$ & $B l$ & $y v g J$ \\
\hline Q126 & 1,520 & 601 & $2 \mathrm{E}-12$ & $5 E-65$ & Bs 168 & yokA \\
\hline Q168 & 540 & 446 & $5 \mathrm{E}-12$ & $3 E-35$ & Bs 168 & $y t 1 R$ \\
\hline Q040 & 560 & 471 & $8 \mathrm{E}-11$ & $6 \mathrm{E}-46$ & Bs 168 & tuaE \\
\hline Q022 & 1,180 & 606 & $1 \mathrm{E}-10$ & $6 \mathrm{E}-08$ & $B s$ & $\operatorname{yod} N$ \\
\hline Q131 & 300 & 268 & $2 \mathrm{E}-10$ & $1 \mathrm{E}-25$ & Bs 168 & yacM \\
\hline Q159 & 650 & 483 & $1 \mathrm{E}-09$ & $1 \mathrm{E}-44$ & $B l$ & ysaA \\
\hline Q133 & 950 & 768 & $3 \mathrm{E}-08$ & $1 \mathrm{E}-77$ & Bs & ipa $77 d$ \\
\hline Q148 & 320 & 302 & $3 \mathrm{E}-06$ & $1 \mathrm{E}-30$ & Bs 168 & $m m g D$ \\
\hline Q071 & 580 & 552 & $6 \mathrm{E}-06$ & $8 \mathrm{E}-21$ & $B l$ & $\lg t$ \\
\hline Q142 & 800 & 356 & $1 \mathrm{E}-05$ & $3 \mathrm{E}-37$ & $B c$ & NA \\
\hline Q124 & 900 & 679 & $3 \mathrm{E}-05$ & $4 \mathrm{E}-56$ & $B s$ & $\operatorname{din} G$ \\
\hline Q125 & 720 & 598 & $9 \mathrm{E}-05$ & $8 \mathrm{E}-27$ & $B s$ & spsD \\
\hline
\end{tabular}

${ }^{a}$ Length of sequence obtained after suppressive subtractive hybridization.

${ }^{b}$ Length of sequence used for BLAST-based comparisons to GenBank.

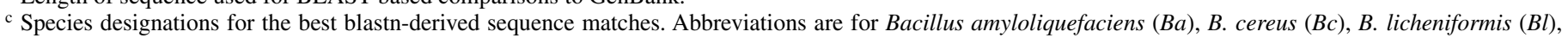
or B. subtilis $(B s)$. Strain names are listed only for previously identified biocontrol strains and the reference strain 168.

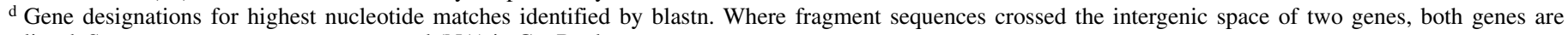
listed. Some sequences were not annotated (NA) in GenBank. 
lates in our collection, and GBO3 was only mildly inhibitory with a score of 1.0. An even larger proportion of Bacillus isolates scored negative for the gene markers displayed activities against $P$. irregulare that were greater than or equal to those of strains harboring the markers, whose average inhibition scores ranged from 1.0 to 2.0. And, interestingly enough, only some of the $B$. cereus isolates and B. pumilus GB34 were maximally antagonistic to Phytophthora sojae in these assays, though QST713 did show a marginal degree of inhibition in all assays (i.e., average score of 1.0).

The association of the targeted gene markers and in vitro inhibition capacities were strongest in $B$. subtilis, where distinctions between presence and absence were multiple. However, similar types of associations were observed in other Bacillus spp. As a group, all of the B. pumilus and B. licheniformis isolates scored (weakly) positive for one or more gene markers and were more inhibitory to $R$. solani $(P=0.01)$ compared with those strains lacking the scored markers. Additionally, the two B. pumilus isolates that were scored weakly positive for the bmy gene (i.e., $1.1 \mathrm{a} 2$ and $2.5 \mathrm{a})$ were significantly more inhibitory to Pythium ultimum than the other isolates lacking all of the markers $(P=$ 0.04). However, presence of the amplifiable markers was not necessarily a good predictor of biocontrol capacity in B. pumilus because the commercialized biocontrol strain GB34 was scored negative for all of the amplifiable targets, yet displayed in vitro inhibition capacities similar to those of the commercialized $B$. subtilis strains GB03, MBI600, and QST713. Additionally, most of the $B$. cereus isolates obtained from Ohio soybean fields were strongly inhibitory to Phytophthora sojae. The presence of the markers was not significantly related to the capacity of the different isolates to inhibit Pythium irregulare $(P=0.39)$ and Phytophthora sojae $(P=0.25)$ in vitro under the conditions tested (Fig. 3$)$.

\section{DISCUSSION}

We characterized over 60,000 bp of genomic sequence obtained from strains of B. subtilis used in two different biocontrol products. Nearly half of the 149 sequences we analyzed were sufficiently different from those presently in GenBank that no functional assignments could be made (data not shown). We expect that many of those unique sequences represent noncoding regions which are likely to be strain specific and therefore of limited value for population studies. Nonetheless, further characterization of these unique sequences is warranted because some may encode novel genes, an unknown fraction of which may be involved in biological control. Of the 80 Bacillus-like sequences we obtained, 65 were associated with genes predicted to encode a variety of metabolic functions. Much research has gone into establishing the function of $B$. subtilis genes, but such work has yet to reveal the function of all of the ORFs identified in strain 168 (48). In addition, their potential roles in bacterial fitness in the natural environment and biocontrol activities in a managed environment remain highly speculative. Nonetheless, several of these gene fragments identified present intriguing new avenues for investigating the nature of antibiotic-mediated biocontrol. For example, $d p p C$ is predicted to code for dipeptide transporters and the homologs identi-

TABLE 3. Oligonucleotide primers used to detect genetic markers for biological control in Bacillus subtilis

\begin{tabular}{|c|c|c|c|c|}
\hline Set & Primer name & Sequence $\left(5^{\prime}-3^{\prime}\right)$ & Target & Amplicon size (bp) \\
\hline \multirow[t]{2}{*}{1} & $44 \mathrm{~F}$ & TAT AGC GCA ATG TAT GTA T & clone Q044 & 135 \\
\hline & $44 \mathrm{R}$ & GTA CTC AAA ATC CAT CTG G & $\ldots$ & $\ldots$ \\
\hline \multirow[t]{2}{*}{2} & $147 \mathrm{~F}$ & CAG AGC GAC AGC AAT CAC AT & yndJ & 212 \\
\hline & $147 \mathrm{R}$ & TGA ATT TCG GTC CGC TTA TC & $\ldots$ & $\ldots$ \\
\hline \multirow[t]{2}{*}{3} & $2 \mathrm{~F}$ & TTC CAC GGC CAT TCC TAT AC & bioA & 210 \\
\hline & $2 \mathrm{R}$ & TTT GTC CCC TTA TCC TGC AC & $\ldots$ & $\ldots$ \\
\hline \multirow[t]{2}{*}{4} & SRFAF1 & GAA AGA GCG GCT GCT GAA AC & srfAA & 273 \\
\hline & SRFAR1 & CCC AAT ATT GCC GCA ATG AC & $\ldots$ & $\ldots$ \\
\hline \multirow[t]{2}{*}{5} & FNDF1 & CCT GCA GAA GGA GAA GTG AAG & fenD & 293 \\
\hline & FNDR1 & TGC TCA TCG TCT TCC GTT TC & $\ldots$ & $\ldots$ \\
\hline \multirow[t]{2}{*}{6} & $110 \mathrm{~F}$ & GTT CTC GCA GTC CAG CAG AAG & $\operatorname{srfAB}$ & 308 \\
\hline & $110 \mathrm{R}$ & GCC GAG CGT ATC CGT ACC GAG & $\ldots$ & $\ldots$ \\
\hline \multirow[t]{2}{*}{7} & $135 \mathrm{~F}$ & GAA CTG TCC GAA ACA TGT CCG & $y n g G$ & 372 \\
\hline & $135 \mathrm{R}$ & CTG AGC TCT TGA ACG GTC CGG & $\ldots$ & $\ldots$ \\
\hline \multirow[t]{2}{*}{8} & $\mathrm{BMBF} 2$ & TGA AAC AAA GGC ATA TGC TC & bmy $B$ & 395 \\
\hline & BMBR2 & AAA AAT GCA TCT GCC GTT CC & $\ldots$ & $\ldots$ \\
\hline \multirow[t]{2}{*}{9} & ITUCF1 & TTC ACT TTT GAT CTG GCG AT & ituC & 575 \\
\hline & ITUCR3 & CGT CCG GTA CAT TTT CAC & $\ldots$ & $\ldots$ \\
\hline
\end{tabular}

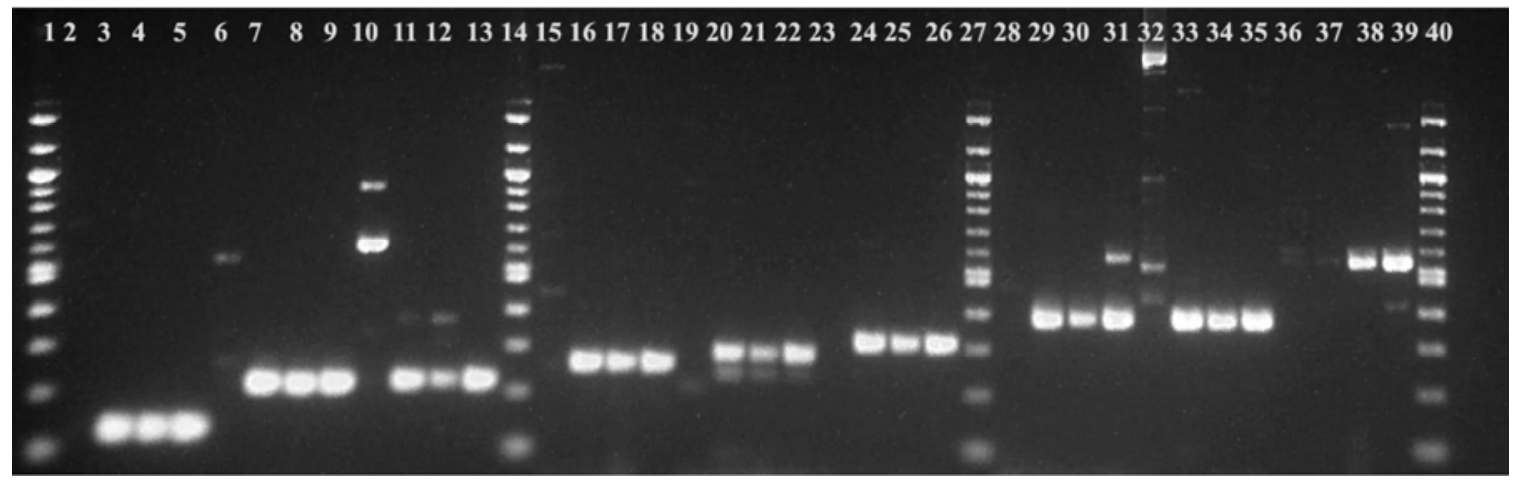

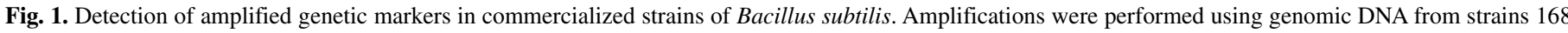

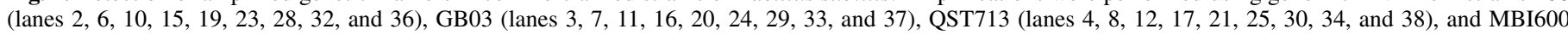

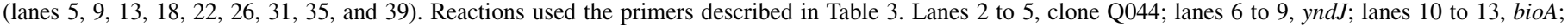

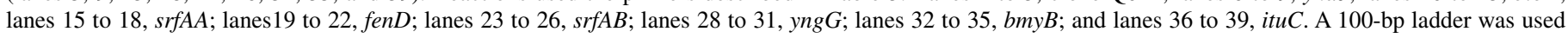
for sizing comparisons (lanes 1, 14, 27, and 40). 
fied in this study may be involved in the secretion or uptake of CLPs or peptide hormones involved in density-dependent signaling. It is known that the synthesis of phenazine antibiotics is regulated in a density-dependent fashion in gram-negative bacteria Pseudomonas chlororaphis (5). Also, B. subtilis uses the ComX and $\mathrm{Phr}$ family of oligopeptides for quorum sensing, which is important for antibiotic production and sporulation during starving or nutrient-deficient conditions $(18,43)$. Further work involving the generation and analyses of gene-disruption mutants will be useful for establishing the involvement of the various genes, marked by the different subtracted fragments, to biological control.

By relying on independent isolations from GB03 and QST713 and comparisons to the small portions of FZB42, RB14, AU195, and $A 1 / 3$ genomic sequences previously deposited in GenBank, we found that just over $10 \%$ of the subtracted fragments we characterized represented viable targets for development. This observation led us to hypothesize that the most effective biocontrol strains of $B$. subtilis shared multiple genetic elements responsible for pathogen suppression. With regards to biocontrol B. subtilis strains initially selected based on in vitro antibiotic production, this hypothesis was substantiated by the PCR-based amplification of eight markers from three different commercialized strains, including MBI600, for which no previous genetic data was available (Fig. 1). This observation reveals a close phylogenetic relationship among three commercialized biocontrol strains, a phenomenon that could be used to more fully delineate the genetic mechanisms responsible for biological disease control in commercially successful $B$. subtilis strains.

We set out to identify genetic markers for biocontrol activities in $B$. subtilis using a comparative genomics approach. In the end, we identified nine genetic elements common to multiple strains of B. subtilis with proven biocontrol activities (Fig. 1). Database searches and genetic screens of multiple Bacillus isolates done as part of this work indicate that the PCR-based assays developed here are likely to identify only strains closely related to the commercialized biocontrol strains GB03, QST713, MBI600, and FZB42. Four such isolates were obtained for Ohio soybean fields and, in vitro, they displayed inhibitory activity against four root pathogens of soybean comparable with that displayed by commercialized biocontrol strains belonging to B. subtilis. Because the spectrum of in vitro inhibition activities did not vary greatly among the isolates harboring the identified gene markers, it seems somewhat unlikely that their spectrum of utility would vary if antibiosis were the primary mechanism of biocontrol. Antibiosis is the one mechanism of biological control that is well characterized genetically and biochemically in Bacillus spp. $(4,15,19)$ as well as other microbes, such as Trichoderma $(22,46,57)$ and Pseudomonas spp. $(7,24,50)$. In B. subtilis, several studies have indicated that, individually or in combination, CLPs contributed to the biological control of different plant pathogens $(4,12,15$, $19,26,34)$. The in vitro assays conducted as part of this work indicate that the types and amounts of inhibitory substances secreted by $B$. subtilis strains vary, but that isolates harboring the markers generally produce a more inhibitory dose than other Bacillus strains (Fig. 3). However, because in vitro assays do not reliably

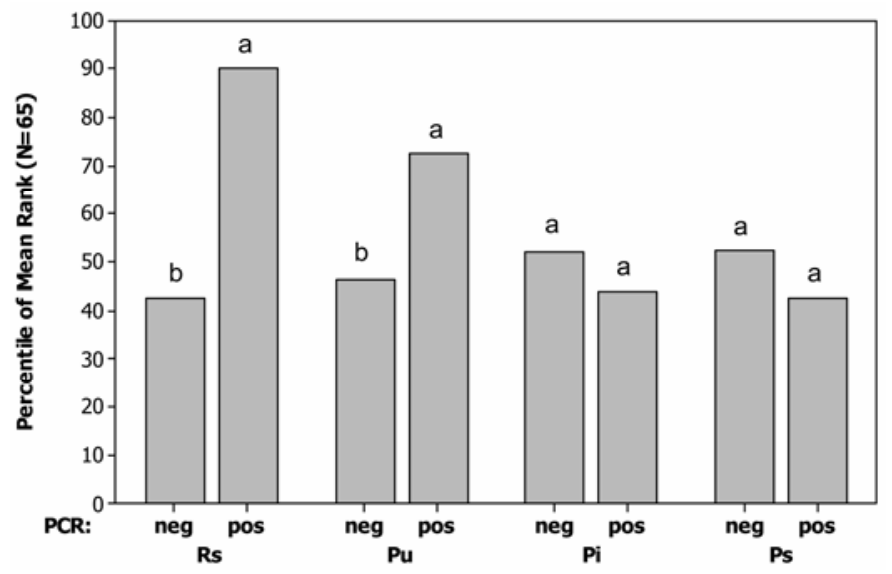

Fig. 3. Variation in biocontrol capacity of Bacillus isolates distinguished by the genetic markers defined in this study. Strains were scored either negative (neg) or positive (pos) for eight or nine of the markers identified in this study. The relative capacity of each isolate to inhibit the growth of Rhizoctonia solani $(\mathrm{Rs})$, Pythium ultimum $(\mathrm{Pu})$, Pythium irregulare $(\mathrm{Pi})$, and Phytophthora sojae $(\mathrm{Ps})$ was assessed in vitro on $1 / 10 \times$ tryptic soy agar. The percentile of the mean rank score is plotted to indicate the relative performance of each group within the collection. For each pathogen, bars labeled with different letters are significantly different based on the Kruskal-Wallis test $(P<0.01)$.
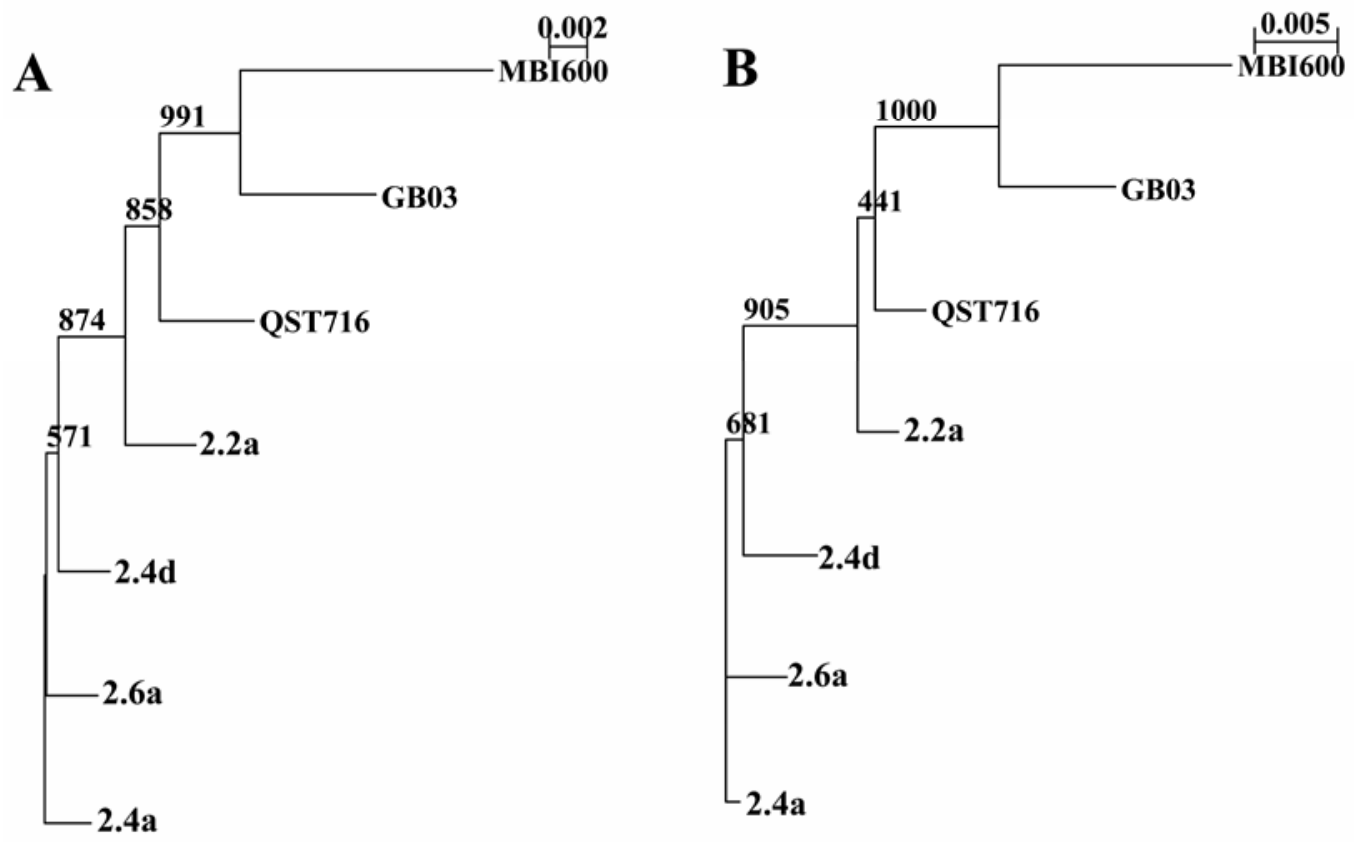

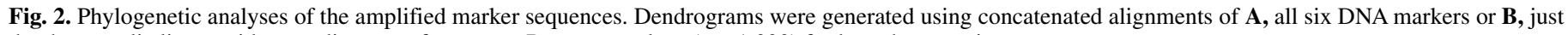
the three cyclic lipopeptide-encoding gene fragments. Bootstrap values $(n=1,000)$ for branches are given. 
predict biocontrol efficacy in the field, additional testing of isolates harboring the amplifiable sequences will be required to establish the extent to which the gene fragments are indeed reliable markers for biocontrol activity.

Recent work characterizing the FZB42 genome (15) suggests that several of the gene fragments we identified were physically linked. In FZB42, four of the markers we identified (bioA, Q044, $y n d J$, and $y n g G$ ) occur on a $122-\mathrm{kb}$ fragment that also contains bmy, fen, and srf genes (GenBank accession nos. AJ475642 and AJ575417). It is intriguing that a disproportionate number of subtracted fragments obtained from GB03 and QST713 map to this section of the genome. It may indicate that, in biocontrol strains, this section of the genome contains other genes important for antibiotic production in particular, or biological control in general. Additional genes of interest undoubtedly occur in B. subtilis because other mechanisms of biocontrol and plant growth promotion have been reported in multiple isolates of the species $(14,27)$. In legume crops, synergy with nitrogen-fixing mutualists may be important. Some strains of B. subtilis have been reported to produce nod factor homologs (20), and inoculations with MBI 600 sometimes can improve soybean yields even when applied to fungicide-treated seed (28). Alternatively, plant growth promotion may be a direct interaction between host and inoculant. Strains GB03 and IN937a produce volatile organic compounds, such as 2,3-butanediol and acetoin, which were found to stimulate plant growth and activate plant host defenses $(44,45)$. Another potential mechanism by which Bacillus spp. could improve plant health is by interfering in bacterial quorum sensing. Bacillus sp. A24 encodes a lactonase enzyme that degrades $N$-acyl-homoserine lactones that may prevent the buildup of the population of plant pathogenic bacteria (33). In our screens, we did not identify any sequences with an obvious linkage to these mechanisms. Thus, more comprehensive screens will be needed to identify the complete pool of $B$. subtilis genes that likely are involved in biological control and plant health promotion. This could be achieved by additional screening of our subtracted libraries or by comparisons of whole genome sequences. Although significantly more expensive than the SSH-based approach used here, whole genome sequence comparisons of multiple biocontrol strains would be most useful for identifying the full complement of genes involved in biological control.

The common genetic elements of GB03, QST713, MBI600, and FZB42 also could be used to study the ecology of these inoculant strains and related natural populations of B. subtilis with biocontrol potential. Marker-based assays have been developed already for studying populations of antibiotic-producing pseudomonads $(8,31,40)$. Such assays already have proven useful for studying both the diversity (16), distribution (30), and population dynamics $(31$; unpublished data) of antibiotic-producing Pseudomonas fluorescens believed to play a significant role in soil suppressiveness (56). It is now possible to perform similar studies for antibiotic-producing B. subtilis. Although the assays described in this work are suitable for characterization of isolates, work currently is underway to allow for quantitative PCR-based assessments of inoculated populations of biocontrol agents, such as GB03 and MBI600, from soil and rhizosphere DNA (unpublished data).

In their current form, the PCR-based assays described in this study may be used to greatly accelerate the discovery of new biocontrol strains of $B$. subtilis. Our sequence analyses revealed that all of the marker-containing isolates were genetically distinct. Still, multiple, commercially successful biocontrol strains (i.e., GB03, MBI600, and QST713) all contain the genetic markers identified in this study (Fig. 1). Each of these commercialized strains is applied primarily to different crops, presumably because the intensive bioassays performed as part of commercial development indicated a degree of specificity in the efficacy of each. Interestingly, three of the four Ohio isolates were most similar to each other, and they were more closely aligned to strains isolated elsewhere (Fig. 2). Additional analyses that included homologous sequences previously cloned from strains FZB42 (15), AU195 (34), and RB14 (4), isolated from different locations worldwide, revealed even more diversity at the nucleotide level. This was particularly true for the two database matches to $\operatorname{bamB}$ from FZB42 and $b m y B$ from AU195. These observations may indicate that, although the species is globally distributed (27), B. subtilis is sedentary in soils relative to the development of evolutionarily distinct subpopulations. We hypothesize that the variation in target or host range is mirrored by the genetic diversity found in the marker sequences amplified from each strain, particularly those functionally related to biocontrol (e.g., bmyB, fenD, and $i t u C$ ).

Other genetic markers have been used to screen for genetic diversity in other species of biocontrol bacteria. Groundbreaking work characterizing diversity and biocontrol potential of $B$. cereus strains involved the use of a genetic marker for zwittermycin A resistance (49). In that work, substantial phenotypic variation, including suppression of damping-off, was observed among the isolates scoring positive for the gene marker and zwittermycin production. That study was the first to indicate that genetic markers could be used to identify significant phenotypic variation among those subspecies of Bacillus displaying biocontrol activities. More recently, Giacomodonato et al. (10) developed degenerate primers targeting peptide synthetase genes cloned from different Bacillus spp. and were able to associate the presence of such genes to inhibition of Sclerotinia sclerotiorum in a small collection of seven Bacillus isolates. Several labs also have used hybridization and PCR-based probes to discover novel genotypes of antibiotic-producing pseudomonads $(8,30,32,55)$. In P. fluorescens, sequence variation in phlD has been correlated with other genome differences $(25,55)$. Interestingly, some of the distinct genotypes display significant phenotypic variation in antibiotic production $(30,41,42,47)$ and rhizosphere competence $(17,36)$. We assert that the diversity of marker sequences can be used as a criterion for selecting novel strains that might be better suited to different biocontrol applications. By using PCR-based screens, large collections of Bacillus spp. could be screened rapidly for marker-containing genotypes prior to intensive phenotypic screening. Additionally, single-pass sequencing would provide an additional criterion for the identification of novel variants. Such an approach could accelerate the rate of discovery of new and useful biocontrol strains and plant growth-promoting rhizobacteria belonging to the species $B$. subtilis.

\section{ACKNOWLEDGMENTS}

This work was funded by the OARDC's Research Enhancement Competitive Grants Program. We thank J. Mesaros for technical assistance and $\mathrm{J}$. Win and S. Kamoun for assistance with sequence analyses and many helpful discussions.

\section{LITERATURE CITED}

1. Akopyants, N. S., Fradkov, A., Diatchenko, L., Hills, J. E., Siebert, P. D., Lukyanov, S. A., Sverdlov, E. D., and Berg, D. E. 1998. PCR based subtractive hybridization and differences in gene content among strains of Helicobacter pylori. Proc. Natl. Acad. Sci. USA 95:13108-13113.

2. Akpa, E., Jacques, P., Wathlet, B., Paquot, M., Fuchs, R., Budzikiewiez, H., and Thonart, P. 2001. Influence of culture conditions on lipopeptide production by Bacillus subtilis. Appl. Biochem. Biotechnol. 91-93:551-561.

3. Altschul, S. F., Gish, W., Miller, W., Myers, E. W., and Lipman, D. L. 1990. Basic local alignment search tool. J. Mol. Biol. 215:403-410.

4. Asaka, O., and Shoda, M. 1996. Biocontrol of Rhizoctonia solani damping off of tomato with Bacillus subtilis RB14. Appl. Environ. Microbiol. 62:4081-4085.

5. Chin-A-Woeng, T. F. C., van den Broek, D., deVoer, G., van der Drift, K. M., Tuinman, S., Thomas-Oates, J. E., Lugtenberg, B. J., and Bloemberg, G. V. 2001. Phenazine-1-Carboxamide production in the biocontrol strain 
Pseudomonas chlororaphis PCL1391 is regulated by multiple factors secreted into the growth medium. Mol. Plant-Microbe Interact. 14:969979.

6. Collins, D. P., Jacobsen, B. J., and Maxwell, B. 2003. Spatial and temporal population dynamics of a phyllosphere colonizing Bacillus subtilis biological control agent of sugar beet Cercospora leaf spot. Biol. Control 26:224-232.

7. de la Fuente, L., Thomashow, L., Weller, D., Bajsa, N., Quagliotto, L., Chernin, L., and Arias, A. 2004. Pseudomonas fluorescens UP61 isolated from birdsfoot trefoil rhizosphere produces multiple antibiotics and exerts a broad spectrum of biocontrol activity. Eur. J. Plant. Pathol. 110:671-681.

8. de Souza, J. T., and Raaijmakers, J. M. 2003. Polymorphisms within prnD and pltC genes from pyrrolnitrin and pyoluteorin-producing Pseudomonas and Burkholderia spp. FEMS Microbiol. Ecol. 43:21-34.

9. Gebhardt, K., Schimana, J., Muller, J., Fiedler, H.-P., Kallenborn, H. G., Holzenkampfer, M., Krastel, P., Zeeck, A., Vater, J., Holtzel, A., Schmid, D. G., Rheinheimer, J., and Dettner, K. 2002. Screening for biologically active metabolites with endosymbiotic bacilli isolated from arthropods. FEMS Microbiol. Lett. 217:199-205.

10. Giacomodonato, M. N., Pettinari, M. J., Souto, G. I., Mendez, B. S., and Lopez, N. I. 2001. A PCR based method for the screening of bacterial strains with antifungal activity in suppressive soybean rhizospheres. World J. Microbiol. Biotechnol. 17:51-55.

11. Hervas, A., Landa, B., Datnoff, L. E., and Jimenez-Diaz, R. M. 1998. Effects of commercial and indigenous microorganisms on Fusarium wilt development in chickpea. Biol. Control 13:166-176.

12. Hofemeister, J., Conrad, B., Adler, B., Hofemeister, B., Feesche, J., Kucheryava, N., Steinborn, G., Franke, P., Grammel, N., Zwintscher, A., Leenders, F., Hitzeroth, G., and Vater, J. 2004. Genetic analysis of the biosynthesis of non-ribosomal peptide-and polyketide like antibiotics, iron uptake and biofilm formation by Bacillus subtilis A 1/3. Mol. Genet. Genomics 272:363-378.

13. Jacobsen, B. J., Zidack, N. K., and Larson, B. J. 2004. The role of Bacillus-based biological control agents in integrated pest management systems: Plant diseases. Phytopathology 94:1272-1275.

14. Kloepper, J. W., Ryu, C.-M., and Zhang, S. 2004. Induced systemic resistance and promotion of plant growth by Bacillus spp. Phytopathology 94:1259-1266.

15. Koumoutsi, A., Chen, X.-H., Henne, A., Liesegang, H., Hitzeroth, G., Franke, P., Vater, J., and Borriss, R. 2004. Structural and functional characterization of gene clusters directing nonribosomal synthesis of bioactive cyclic lipopeptides in Bacillus amyloliquefaciens strain FZB42. J. Bacteriol. 186:1084-1096.

16. Landa, B. B., Mavrodi, O. V., Raaijmakers, J. M., McSpadden Gardener, B. B., Thomashow, L. S., and Weller, D. M. 2002. Differential ability of genotypes of 2,4-diacetylphloroglucinol producing Pseudomonas fluorescens strains to colonize the roots of pea plants. Appl. Environ. Microbiol. 68:3226-3237.

17. Landa, B. B., Mavrodi, D. M., Thomashow, L. S., and Weller, D. M. 2003. Interactions between strains of 2,4-diacetylphloroglucinol-producing Pseudomonas fluorescens in the rhizosphere of wheat. Phytopathology 93:982-994.

18. Lazazzera, B. A. 2001. The intracellular function of extracellular signaling peptides. Peptides 22:1519-1527.

19. Leifert, C., Li, H., Chidburee, S., Hampson, S., Workman, S., Sigee, D., Epton, H. A. S., and Harbour, A. 1995. Antibiotic production and biocontrol activity by Bacillus subtilis CL27 and Bacillus pumilus CL45. J. Appl. Bacteriol. 78:97-108.

20. Lian, B., Prithviraj, B., Souleimanov, A., and Smith, D. L. 2001. Evidence for the production of chemical compounds analogous to nod factor by the silicate bacterium Bacillus circulans GY92. Microbiol. Res. 156:289-292.

21. Loeffler, W., Tschen, J. S. M., Vanittanakom, N., Kugler, M., Knorpp, E., and $\mathrm{Wu}, \mathrm{T}$. G. 1986. Antifungal effects of bacilysin and fengycin from Bacillus subtilis F29-3. A comparison with activities of other Bacillus antibiotics. J. Phytopathol. 115:204-213.

22. Lorito, M., Farkas, V., Rebuffat, S., Bodo, B., and Kubicek, C. P. 1996. Cell wall synthesis is a major target of Mycoparasitic antagonism by Trichoderma harzianum. J. Bacteriol. 178:6382-6385.

23. Marahiel, M. A., Stachelhaus, T., and Mootz, H. D. 1997. Modular peptide synthetases involved in nonribosomal peptide synthesis. Chem. Rev. 97:2651-2673.

24. Maurhofer, M., Keel, C., Haas, D., and Défago, G. 1995. Influence of plant species on disease suppression by Pseudomonas fluorescens strain CHA0 with enhanced antibiotic production. Plant Pathol. 44:40-50.

25. Mavrodi, D. V., Mavrodi, O. V., McSpadden Gardener, B. B., Landa, B. B., Weller, D. M., and Thomashow, L. S. 2002. Identification of differences in genome content among phlD-positive Pseudomonas fluorescens strains by using PCR based subtractive hybridization. Appl. Environ. Microbiol. 68:5170-5176.
26. McKeen, C. D., Rielly, C. C., and Pusey, P. L. 1986. Production and partial characterization of antifungal substances antagonistic to Monilinia fructicola from Bacillus subtilis. Phytopathology 76:136-139.

27. McSpadden Gardener, B. B. 2004. Ecology of Bacillus and Paenibacillus spp. in agricultural systems. Phytopathology 94:1252-1258.

28. McSpadden Gardener, B. B., and Beuerlein, J. B. 2004. Evaluation of rhizobial inoculants with and without Bacillus subtilis MBI600 on soybeans in Ohio, 2003. Biol. Cult. Tests DOI:10.1094/BC19:FC035.

29. McSpadden Gardener, B. B., and Fravel, D. R. 2002. Biological control of plant pathogens: Research, commercialization, and application in the USA. Online. Plant Health Progress DOI:10.1094/PHP-2002-0510-01RV.

30. McSpadden Gardener, B. B., Gutierrez, L. J., Joshi, R., Edema, R., and Lutton, E. 2005. Distribution and biocontrol potential of phlD Pseudomonas in corn and soybean fields. Phytopathology 95:715-724.

31. McSpadden Gardener, B. B., Mavrodi, D. V., Thomashow, L. S., and Weller, D. M. 2001. A rapid PCR-based assay characterizing rhizosphere populations of 2,4-DAPG-producing bacteria. Phytopathology 91:44-54.

32. McSpadden Gardener, B. B., Schroeder, K. L., Kalloger, S. E., Raaijmakers, J. M., Thomashow, L. S., and Weller, D. M. 2000. Genotypic and phenotypic diversity of phlD containing Pseudomonas spp. strains isolated from the rhizosphere of wheat. Appl. Environ. Microbiol. 66:1939-1946.

33. Molina, L., Constantinescu, F., Michel, L., Reimmann, C., Duffy, B., and Défago, G. 2003. Degradation of pathogen quorum-sensing molecules by soil bacteria: A preventive and curative biological control mechanism. FEMS Microbial. Ecol. 45:71-81.

34. Moyne, A.-L., Cleveland, T. E., and Tuzun, S. 2001. Molecular characterization and analysis of the operon encoding the antifungal lipopeptide bacillomycin D. FEMS Microbiol. Lett. 234:43-49.

35. Murphy, J. F., Zehnder, G. W., Schuster, D. J., Sikora, E. J., Polston, J. E., and Kloepper, J. W. 2000. Plant growth-promoting rhizobacterial mediated protection in tomato against Tomato mottle virus. Plant Dis. 84:779-784.

36. Okubara, P. A., Kornoely, J. P., and Landa, B. B. 2004. Rhizosphere colonization of hexaploid wheat by Pseudomonas fluorescens strains Q8r1-96 and Q2-87 is cultivar-variable and associated with changes in gross root morphology. Biol. Control 30:3932-403.

37. Ongena, M., Duby, F., Jourdan, E., Beaudry, T., Jadin, V., Dommes, J., and Thonart, P. 2005. Bacillus subtilis M4 decreases plant susceptibility towards fungal pathogens by increasing host resistance associated with differential gene expression. Appl. Microbiol. Biotechnol. 67:692-698.

38. Ongena, M., Jacques, P., Toure, Y., Destain, J., Jabrane, A., and Thonart, P. Involvement of fengycin-type lipopeptides in the multifaceted biocontrol potential of Bacillus subtilis. Appl. Microbiol. Biotechnol. DOI: 10.1007/s00253-005-1940-3.

39. Perrière, G., and Gouy, M. 1996. WWW-Query: An on-line retrieval system for biological sequence banks. Biochimie 78:364-369.

40. Raaijmakers, J. M., Weller, D. M., and Thomashow, L. S. 1997. Frequency of antibiotic producing Pseudomonas spp. in natural environments. Appl. Environ. Microbiol. 63:881-887.

41. Ramette, A., Moënne-Loccoz, Y., and Défago, G. 2001. Polymorphism of the polyketide synthase gene phlD in biocontrol fluorescent Pseudomonads producing 2,4-diacetylphloroglucinol and comparison of phlD with plant polyketide synthases. Mol. Plant-Microbe Interact. 14:639-652.

42. Ramette, A., Moënne-Loccoz, Y., and Défago, G. 2003. Prevalence of fluorescent pseudomonads producing antifungal phloroglucinols and/or hydrogen cyanide in soils naturally suppressive or conducive to tobacco black root rot. FEMS Microbiol. Ecol. 44:35-43.

43. Ren, D., Bedzyk, L. A., Setlow, P., Thomas, S. M., Ye, R. W., and Wood, T. K. 2004. Gene expression in Bacillus subtilis surface biofilms with and without sporulation and the importance of yveR for biofilm maintenance. Biotechnol. Bioeng. 86:344-364.

44. Ryu, C.-M., Farag, M. A., Hu, C.-H., Reddy, M. S., Wei, H.-X., Pare, P. W. and Kloepper, J. W. 2003. Bacterial volatiles promote growth in Arabidopsis. Proc. Natl. Acad. Sci. USA 100:4927-4932.

45. Ryu, C.-M., Hu, C.-H., Reddy, M. S., and Kloepper, J. W. 2003. Different signaling pathways of induced resistance by rhizobacteria in Arabidopsis thaliana against two pathovars of Pseudomonas syringae. New Phytol. 160:413-420.

46. Schirmbock, M., Lorito, M., Wang, Y. L., Hayes, C. K., Arisan-Atac, I., Scala, F., Harman, G. E., and Kubicek, C. P. 1994. Parallel formation and synergism of hydrolytic enzymes and peptaibol antibiotics, molecular mechanisms involved in the antagonistic action of Trichoderma harzianum against phytopathogenic fungi. Appl. Environ. Microbiol. 60:4364-4370.

47. Sharifi-Tehrani, A., Zala, M., Natsch, A., Moënne-Loccoz, Y., and Défago, G. 1998. Biocontrol of soil-borne fungal plant diseases by 2,4-diacetylphloroglucinol-producing fluorescent pseudomonads with different restriction profiles of amplified 16S rDNA Eur. J. Plant Pathol. 104: 631-643. 
48. Sonenshein, A. L., Hoch, J. A., and Losick, R. (eds.) 2002. Bacillus subtilis and Its Closest Relatives: From Genes to Cells. American Society for Microbiology, Washington, D.C.

49. Stabb, E. V., Jacobson, L. M., and Handelsman, J. 1994. Zwittermycin Aproducing strains of Bacillus cereus from diverse soils. Appl. Environ. Microbiol. 60:4404-4412.

50. Thomashow, L. S., and Weller, D. M. 1988. Role of a phenazine antibiotic from Pseudomonas fluorescens in biological control of Gaeumannomyces gramii var. tritici. J. Bacteriol. 170:3499-3450.

51. Thompson, J. D., Gibson, T. J., Plewniak, F., Jeanmougin, F., and Higgins, D. G. 1997. The CLUSTAL_X windows interface: Flexible strategies for multiple sequence alignment aided by quality analysis tools. Nucleic Acids Res. 25:4876-4882.

52. Toure, Y., Ongena, M., Jacques, P., Guiro, A., and Thonart, P. 2004. Role of lipopeptides produced by Bacillus subtilis GA1 in the reduction of grey mould disease caused by Botrytis cinerea on apple. J. Appl. Microbiol. 96:1151-1160.
53. Tsuge, K., Akiyama, T., and Shoda, M. 2001, Cloning, sequencing, and characterization of the Iturin A operon. J. Bacteriol. 183:6265-6273.

54. Validov, S., Mavrodi, O., de la Fuente, L., Boronin, A., Weller, D. Thomashow, L., and Mavrodi, D. M. 2005. Antagonistic activity among 2,4-diacetylphloroglucinol producing fluorescent Pseudomonas spp. FEMS Microbiol. Lett. 242:249-256.

55. Wang, C., Ramette A., Punjasamarnwong, P., Zala, M., Natsch, A., Moënne-Loccoz, Y., and Défago, G. 2001. Cosmopolitan distribution of phlD-containing dicotyledonous crop-associated biocontrol pseudomonads of worldwide origin. FEMS Microbiol. Ecol. 37:105-116.

56. Weller, D. M., Raaijmakers, J. M., McSpadden Gardener, B. B., and Thomashow, L. S. 2002. Microbial populations responsible for specific soil suppressiveness to plant pathogens. Annu. Rev. Phytopathol. 40:309-348.

57. Wiest, A., Grzegorski, D., Bi-Wen, X., Christophe, G., Rebuffat, S., Ebbole, D. J., Bodo, B., and Kenerley, C. 2002. Identification of peptaibols from Trichoderma virens and cloning of a peptabiol synthetase. J. Biol. Chem. 277:20862-20868. 